\title{
Research Article:
}

\section{A Retrospective Analysis of Inflammatory Factors in Adult Patients With Cutaneous Vasculitis}

\author{
Vahide Lajevardi ${ }^{1}, Z_{\text {Zahra Hallaji }}{ }^{1}$, Iraj Shekari ${ }^{2}$, Zohre Khodashenas ${ }^{1 *}$ (D) \\ 1. Department of Dermatology, School of Medicine, Tehran University of Medical Sciences, Tehran, Iran. \\ 2. School of Medicine, Tehran University of Medical Sciences, Tehran, Iran.
}

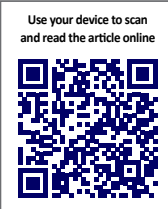

Citation Khodashenas Z, Lajevardi V. A Retrospective Analysis of Inflammatory Factors in Adult Patients With Cutaneous Vasculitis . Immunoregulation. 2019; 1(2):113-117. http://dx.doi.org/10.32598/Immunoregulation.1.2.107

doi : http://dx.doi.org/10.32598/Immunoregulation.1.2.107

Funding: See Page 117

(c) Copyright: The Author(s)

Article info:

Received: 15 September 2017

Accepted: 28 January 2018

Available Online: 01 Jan 2019

Keywords:

Vasculitis, Cutaneous vasculitis, Inflammatory factors

\begin{abstract}
A B S T RA C T
Background: Cutaneous vasculitis is defined as the inflammation of blood vessels of the dermis. However cutaneous vasculitis is not a specific disease but a manifestation that can be seen in a variety of settings. We sought to review the clinical manifestations, laboratorial findings, pathological changes and etiologic association of cutaneous vasculitis in patients admitted to Dermatology Department of Razi Hospital from 1998 to 2011.
\end{abstract}

Materials and Methods: In this retrospective study, we enrolled all patients with records of histological diagnosis of vasculitis between 1998 and 2011 in Razi Hospital. Clinical presentation and inflammatory factors were evaluated, too.

Results: We studied 56 patients with cutaneous vasculitis. 35 (62.5\%) patients were female and 20 (37.5\%) were male. About $75 \%$ of patients had hypersensitivity vasculitis, $10.6 \%$ Henoch-Schonlein purpura, $9 \%$ urticarial vasculitis, and $5.4 \%$ polyarteritis nodosa.

Conclusion: It seems that hypersensitivity vasculitis is the most common form of cutaneous vasculitis. The main clinical manifestations of hypersensitivity vasculitis are skin and joint symptoms.

\section{Introduction}

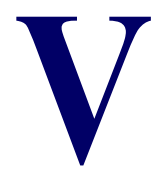

asculitis represents a specific pattern of inflammation of blood vessel walls and can occur in any organ of the body. $\mathrm{Cu}-$ taneous vasculitis can be localized to the skin or less commonly to extra cutaneous organs [1-3]. Vasculitis can affect small, medium or large vessels of the arterial and or venous system [3-5].
Various classification systems have categorized vasculitis syndromes. Diagnosis is based on careful assessment of clinical findings, serologic tests, and histopathologic findings $[3,5,6]$. Skin is an accessible tissue for biopsy. Skin manifests injury to vessels by circulating immune complexes, anti-endothelial cell antibodies, and Cell Mediated Immunity (CMI) [3, 7]. In this retrospective study, we enrolled all patients with records of histological diagnosis of vasculitis Razi Hospital between

\footnotetext{
* Corresponding Author:

Zohre Khodashenas, $M D$

Address: Department of Dermatology, School of Medicine, Tehran University of Medical Sciences, Tehran, Iran.

Phone: +98 (903) 1119779

E-mail: zohrekhodashenas@ymail.com
} 
1998 and 2011 in. We were interested in the clinical manifestation, laboratorial finding, pathological changes and etiologic association of cutaneous vasculitis. The study was approved by the ethic committee

\section{Materials and Methods}

We enrolled all patients with histological diagnosis of cutaneous vasculitis admitted to Dermatology Department of Razi Hospital from March 1998 to December 2011. Histopathological criteria were hyalinization or fibrinoid necrosis of vessels, neutrophilic infiltration, nuclear dust from leukocytoclasis, red blood cell extravasation, and thrombi [3]. Based on these criteria, 56 patients were recruited in the study. A dermatologist collected patients' demographic and medical information including sex, age, clinical history and examination results, body area affected, and family history of vasculitis, presence of systemic symptoms or signs, etiological factors, and laboratory findings. Our classification system was based on the definitions proposed by the CHCC (Chapel Hill Consensus Conference) in 1994 [8].

\section{Statistical analysis}

All the obtained data were analyzed in SPSS 18.0. We used descriptive statistics, Independent samples t test and $\chi^{2}$ test for data analysis. Statistical significance was set at 0.05 .

\section{Results}

Out of 56 histopathologically-proven patients with cutaneous vasculitis who were analyzed in this study, $35(62.5 \%)$ were females and $21(37.5 \%)$ males. Their mean age was 39.5 years, ranged from 5 to 79 years. The mean age of male and female patients at the onset of disease was 41.42 and 37.62 year, respectively. There was no significant difference between males and females in the onset of disease $(\mathrm{P}>0.05)$.

Table 1 lists the cutaneous manifestations of vasculitis. All patients had lesions on their lower limbs (100\%). There were 41 (73.2\%) patients with upper limb lesions, $31(55.4 \%)$ with anterior trunk lesions, 23 (41.1\%) with posterior trunk lesions, 18 (32.1\%) with head and neck lesions, 8 (14.3\%) with palms and soles lesions, 9 (16.1\%) with mucous membrane lesions, and 2 (3.6\%) with genitalia lesions. Cutaneous manifestations are shown in Figure 1. Papule/plaque lesion was the most common type of cutaneous manifestations seen in 58.9\% of patients and the second most was petechial/purpura seen in $57.1 \%$ of patients.

The most common symptoms in our patients were pain in $69.6 \%$, burning sensation in $37.5 \%$, pruritus in $26.8 \%$, and no symptoms in $3.6 \%$ of patients. Table 2 presents the summary of the laboratory results. Elevated Erythrocyte Sedimentation Rate (ESR) found in 27 (48.2\%) patients, anemia in $32.1 \%$, and urinary abnormalities in $23.2 \%$. In 18 patients with urinary abnormalities, 13 had microscopic hematuria and 5 had proteinuria alone. With respect to clinical classification, most of the patients (42 patients, 75\%) were classified as Hypersensitivity Vasculitis (HSV), 6 (10.7\%) patients as Henoch-Schonlein Purpura (HSP), 5 (9\%) patients as urticarial vasculitis, and 3(5.4\%) patients as Polyarteritis Nodosa (PAN). Pathological changes are presented in Figure 2.

Table 1. Cutaneous site of lesions

\begin{tabular}{|ccc|}
\hline Site of Lesion & No. & $\%$ \\
\hline Lower extremities & 56 & 100 \\
\hline Upper extremities & 41 & 73.2 \\
\hline Anterior trunk & 31 & 55.4 \\
\hline Posterior trunk & 23 & 41.1 \\
\hline Head and neck & 18 & 31.2 \\
\hline Palms and soles & 8 & 14.3 \\
\hline Genitalia & 2 & 3.6 \\
\hline Mucous membrane & 9 & 16.1 \\
\hline
\end{tabular}


Table 2. Laboratory findings

\begin{tabular}{|c|c|c|}
\hline Laboratorial Findings & No. & $\%$ \\
\hline Hematuria & 13 & 23.2 \\
\hline Proteinuria & 5 & 8.9 \\
\hline High $\mathrm{Cr}$ & 3 & 5.4 \\
\hline Leukocytosis & 8 & 14.3 \\
\hline Eosinophilia & 2 & 3.6 \\
\hline Leukopenia & 2 & 3.6 \\
\hline Anemia & 15 & 26.8 \\
\hline High ESR & 27 & 48.2 \\
\hline Positive ANA & 3 & 5.4 \\
\hline Positive CRP & 7 & 12.5 \\
\hline Low complement & 2 & 3.6 \\
\hline High AST/ALT & 4 & 7.1 \\
\hline Platelet abnormality & 9 & 16 \\
\hline
\end{tabular}

IMMUNoREGULATION

Direct immunofluorescence study was positive in 54.5\% of patients that showed IgM deposition in the dermal vessels in $18.2 \%$ of the patients; IgG deposition in $18.2 \%$, IgA deposition in $9.2 \%$ and $\mathrm{C} 3$ deposition in $9.2 \%$.

Most extracutaneous involvement was lower limb edema in $44.6 \%$ patients and Joint involvement, arthralgia in $35.7 \%$ and arthritis in $10.7 \%$ of patients (Table 3 ). Various etiologies and/or other associated conditions that were evaluated in our patients were as follows: $40 \%$ of patients with urticarial vasculitis had history of drug consumption, $23.8 \%$ of patients with HSV had history of drug consumption (the most used drugs were penicillin, cefexime, cephalexin, diclofenac, naproxen, atenolol, nortriptyline, and Aspirin), $16.7 \%$ of patients with HSV had infection (a patient with $\mathrm{B}$ hepatitis, a patient with $\mathrm{C}$ hepatitis, a patient with tuberculosis and two patients with nasopharyngeal streptococcal infection). Two (4.8\%) patients of HSV group had malignancy (ALL and gastric adenocarcinoma). One patient had Systemic Lupus Erythematous SLE. Over a half of the patients (21 patients

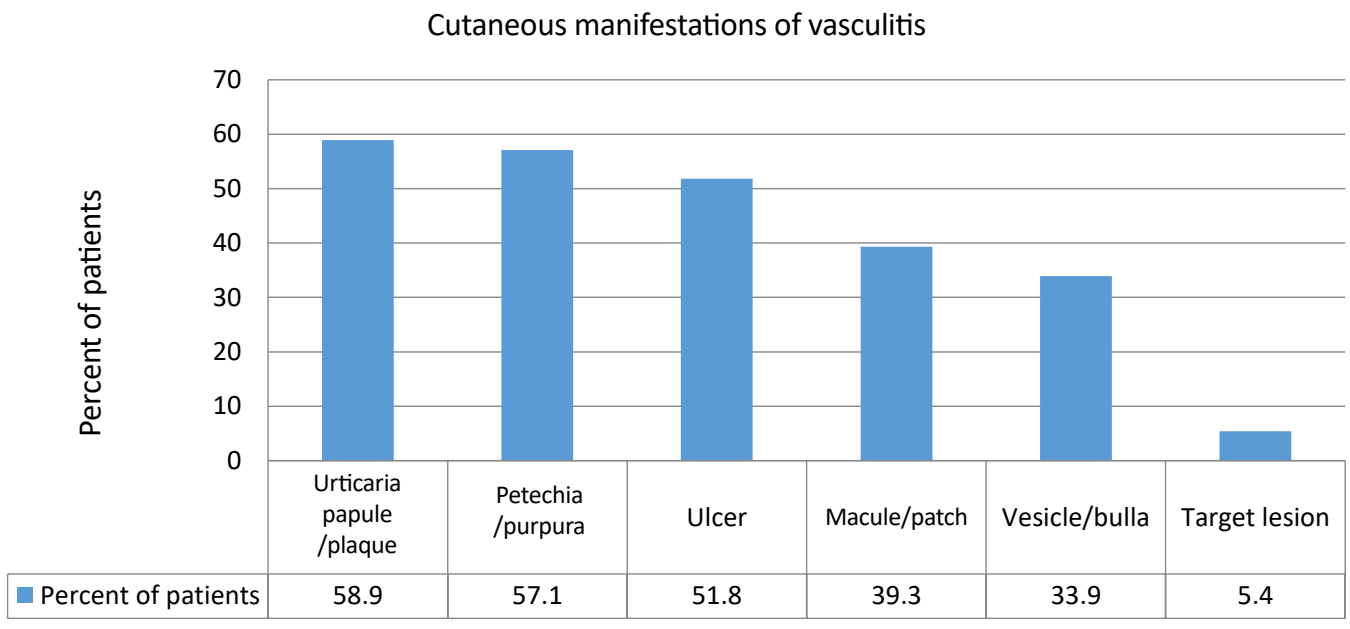

Figure 1. Cutaneous manifestations of vasculitis 
Table 3. Extracutaneous involvement

\begin{tabular}{ccc}
\hline Other Sign and Symptoms & No. & $\%$ \\
\hline Arthralgia & 20 & 35.7 \\
\hline Arthritis & 6 & 10.7 \\
\hline Lower limb edema & 25 & 44.6 \\
\hline Face edema & 2 & 3.6 \\
\hline Inguinal LAP & 3 & 5.4 \\
\hline Gross hematuria & 1 & 1.8 \\
\hline Headache & 2 & 3.6 \\
\hline Abdominal pain & 4 & 7.1 \\
\hline Fever & 10 & 17.9 \\
\hline Weight loss & 8 & 14.3 \\
\hline Epistaxis & 2 & 3.6 \\
\hline
\end{tabular}

IMmunoRegulatios

or $50 \%$ ) were classified as primary cutaneous small vessel vasculitis or idiopathic cutaneous manifestation.

\section{Discussion}

In this study, hypersensitivity vasculitis accounts for the majority of patients $(75 \%)$ which is similar to the prevalence reported in previous studies $[3,9,10]$. However our rate is higher than other studies. Maybe different researchers have used different criteria for classification of patients, such as the American College of Rheumatology criteria and the Chapel Hill Congress Conference definitions, which identify different types of vasculitis $[5,10,11]$.
Most of our patients lacked any underlying cause which is compatible with the recent reports that about $40 \%-60 \%$ of all cutaneous vasculitis have unknown etiology [3, 10-12].

Compatible with other studies, lower incidence of HSP in our study is justified because HSP mainly involves children $[10,11]$. In our patients with known etiology, drugs and infections were the most common etiology with $30.3 \%$ prevalence, which is compatible with previous reports by Carlson et al. and Nawaf A $[5,10]$. In Nawaf A study [10], antibiotics were the most common cause of drug induced vasculitis. Urticarial papule/ plaque $(58.9 \%)$ and petechia/purpura $(57.1 \%)$ constituted the most common manifestation of cutaneous vasculitis in this study, which is different by previously reported

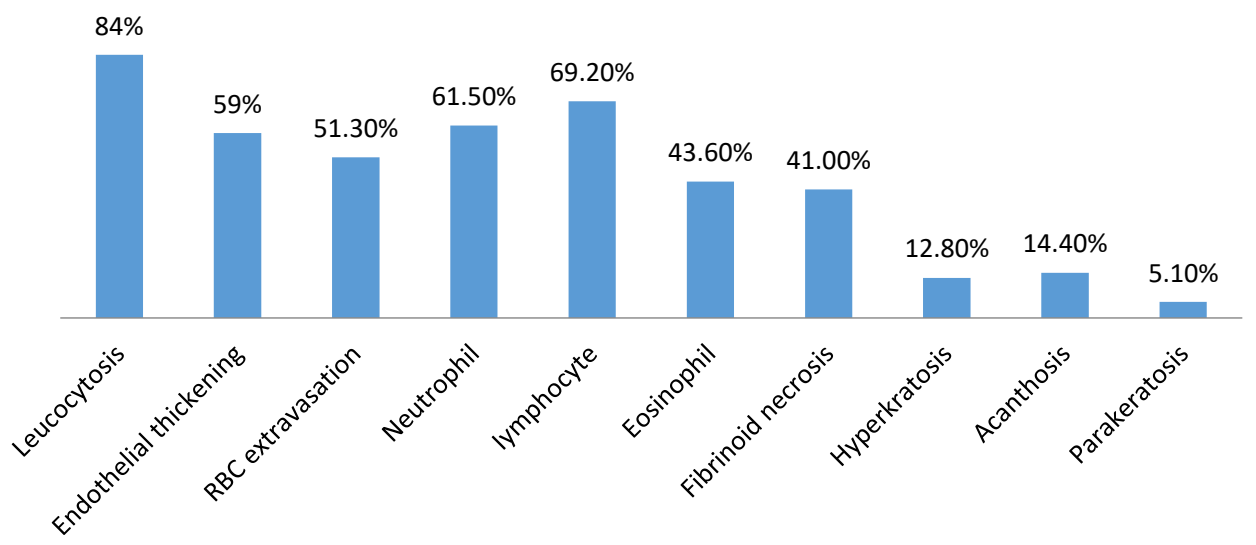

Figure 2. Pathological change

IminoRegelation 
values that palpable purpura constituted the most common manifestation of cutaneous vasculitis $[10,13,14]$.

Multisystem organ involvement including joints, muscles, urinary system, gastrointestinal, lungs, heart and peripheral nerves has been reported in up to $50 \%$ of patients [10], similar to the our study. Laboratory findings in our study is similar with other studies $[3,10]$.

\section{Ethical Considerations}

\section{Compliance with ethical guidelines}

All ethical principles were considered in this article. The participants were informed about the purpose of the research and its implementation stages; They were also assured about the confidentiality of their information; Moreover, They were allowed to leave the study whenever they wish, and if desired, the results of the research would be available to them. The study was approved by the ethic committee of University of Tehran.

\section{Funding}

The paper was extracted from MD thesis authored by Iraj Shekari approved by the School of Medicine at Tehran University of Medical Sciences.

\section{Conflict of interest}

The authors declare no conflict of interest.

\section{Acknowledgements}

This study was carried out by Department of Dermatology at the Tehran University of Medical Sciences. We would like to appreciate all participants who participated in this study.

\section{References}

[1] Chen KR, Carlson JA. Clinical approach to cutaneous vasculitis. American Journal of Clinical Dermatology. 2008; 9(2):7192. [DOI:10.2165/00128071-200809020-00001] [PMID]

[2] Gonzalez-Gay MA, Garcia-Porrua C, Pujol RM. Clinical approach to cutaneous vasculitis. Current Opinion in Rheumatology. 2005; 17(1):56-61. [PMID]

[3] Tai YJ, Chong AH, Williams RA, Cumming S, Kelly RI. Retrospective analysis of adult patients with cutaneous leukocytoclastic vasculitis. Australasian Journal of Dermatology. 2006; 47(2):92-6. [DOI:10.1111/j.1440-0960.2006.00239.x] [PMID]
[4] Crowson AN, Mihm Jr MC, Magro CM. Cutaneous vasculitis: A review. Journal of Cutaneous Patholog. 2003; 30(3):161-73. [DOI:10.1034/j.1600-0560.2003.00033.x]

[5] Carlson JA, Ng BT, Chen KR. Cutaneous vasculitisuptodate: diagnostic criteria, classification, epidemiology, etiology, pathogenesis, evaluation and Prognosis. The American Journal of Dermatopathology. 2005; 27(6):504-28. [DOI:10.1097/01.dad.0000181109.54532.c5]

[6] Sunderkouer C, Sindrilaru A. Clinical classification of vasculitis. European Journal of Dermatology. 2006; 16(2):114-124. [PMID]

[7] Stone JH, Nousari HC. "Essential" cutaneous vasculitis: What every rheumatologist should know about vasculitis of the skin. Current Opinion in Rheumatology. 2001; 13(1):2334. [DOI:10.1097/00002281-200101000-00005] [PMID]

[8] Jennette JC, Falk RJ, Andrassy K, Bacon PA, Churg J, Gross WL, et al. Nomenclature of systemic vasculitides. Arthritis \& Rheumatism. 1994; 37(2):187-92. [DOI:10.1002/art.1780370206] [PMID]

[9] Blanco R, Martínez-Taboada VM, Rodríguez-Valverde V, GarcíaFuentes M. Cutaneous vasculitis in children and adults: Associated diseases and etiologic factors in 303 patients. Medicine. 1998; 77(6):403-18. [DOI:10.1097/00005792-199811000-00006]

[10] Al-Mutairi N. Spectrum of cutaneous vasculitis in adult patients from the farwaniya region of Kuwait. Medical Principles and Practice. 2008; 17(1):43-8. [DOI:10.1159/000109589] [PMID]

[11] Lane SE, Watts RA, Barker TH, Scott DG: Evaluation of the Sorensen diagnostic criteria in the classification of systemic vasculitis. Rheumatology. 2002; 41(10):1138-41. [DOI:10.1093/rheumatology/41.10.1138]

[12] Jennette JC, Falk RJ, Bacon PA, Basu N, Cid MC, Ferrario F, et al. Arthritis and Rheumatism. American Rheumatology 2013; 65:1-11.

[13] Sais G, Vidaller A, Jucglà A, Servitje O, Condom E, Peyrí J. Prognostic factors in leukocytoclasticvasculitis: a clinicopathologicstudy of 160 patients. Archives of Dermatology. 1998; 134(3):309-15. [DOI:10.1001/archderm.134.3.309] [PMID]

[14] Hodge SJ, Callen JP, Ekenstam E. Cutaneous leukocytoclastic vasculitis: Correlation of histopathological changes with clinical severity and course. Journal of Cutaneous Pathology. 1987; 14(5):279-84. [DOI:10.1111/j.1600-0560.1987.tb00500.x] [PMID] 